\title{
PRODUKTIVITAS ALAT TANGKAP PURSE SEINE UNTUK IKAN PELAGIS KECIL DI PANTAI UTARA JAWA
}

\author{
Budi Iskandar Prisantoso") dan Lilis Sadiyah")
}

\begin{abstract}
ABSTRAK
Informasi tentang produktivitas alat tangkap utama ikan pelagis kecil di pantai utara Jawa yaitu purse seine sangat diperlukan untuk memperoleh informasi upaya penangkapan optimum yang berkelanjutan. Tujuan dari riset ini adalah a) untuk memperoleh data dan informasi tentang faktor-faktor yang mempengaruhi hasil tangkapan purse seine; dan b) memperoleh persamaan regresi untuk menduga produktivitas dari purse seine. Data telah dikumpulkan dari bulan Juli sampai dengan Desember 2004. Data tersebut dianalisis dengan menggunakan persamaan regresi terhadap komponen utama dan regresi polynomial. Hasil analisis menunjukkan bahwa variabel yang paling besar pengaruhnya terhadap hasil tangkapan purse seine di pantai utara Jawa adalah faktor kecepatan kapal saat tawur.
\end{abstract}

KATA KUNCI: produktivitas alat tangkap, purse seine, pelagis kecil, pantai utara Jawa

ABSTRACT: Productivity of purse seine for small pelagic fish on the north coast of the Java Sea. By: Budi Iskandar Prisantoso and Lilis Sadiyah

Information about productivity of fishing gear for small pelagic fish in the north coast of the Java i.e. purse seine is needed in order to obtain information about the optimum sustainable effort. The objectives of this research ane a) to gather data and information of various factors that affect to the catch of purse seine; and b) to obtain regression equation to estimate its productivity. Data were collected from July to December 2004. The data were analyzed by principal component regression equation and polynomial regression. The results show that setting speed highly effected to the catch.

KEYWORDS: productivity of fishing gear, purse seine, small pelagic, north coast of the Java Sea

\section{PENDAHULUAN}

Meningkatnya aktivitas kehidupan manusia menuntut eksploitasi sumber daya alam yang semakin bertambah. Perubahan orientasi pembangunan ke laut telah memacu proses pembangunan dan kegiatan pemanfaatan sumber daya laut. Tekanan terhadap kebutuhan sumber daya ikan pelagis kecil berakibat pada penurunan kemampuan ekosistem laut menyediakan sumber daya tersebut, hal ini diakibatkan oleh laju recruitment yang lebih rendah dibandingkan dengan laju kematian yang disebabkan aktivitas penangkapan.

Laut Jawa merupakan salah satu perairan yang telah dieksploitasi secara intensif sejak lama, termasuk di dalamnya perairan pantai utara Jawa (Atmadja et al., 2003). Hasil tangkapan ikan pelagis kecil dari tahun ke tahun terus meningkat. Jumlah kapal semakin meningkat dengan ukuran kapal dan jaring yang semakin besar. Penggunaan kapal yang lebih besar memungkinkan nelayan untuk menjangkau daerah penangkapan yang lebih jauh dengan muatan yang lebih banyak serta hari layar yang semakin lama. Daerah penangkapan telah bergeser semakin jauh dengan hari layar yang semakin lama, dengan demikian terjadi kenaıkan intensitas penangkapan pada daerah penangkapan yang lebih jauh, sedangkan hal yang sebaliknya terjadi pada daerah penangkapan yang lebih dekat dengan pelabuhan perikanan (Edi Muljadi Amin \& Suwarso, 1990). Purse seine (contoh pada Lampiran 4) telah dikenal di pantai utara Jawa sejak awal tahun 1970-an dan ternyata purse seine ini memang potensial dan produktivitas hasil tangkapannya tinggi.

Upaya pencarian tingkat pemanfaatan sumber daya ikan pelagis kecil di pantai utara Jawa yang dalam jangka panjang memberikan hasil tangkapan optimum sangat diperlukan. Oleh karena itu, perlu diketahui tingkat produktivitas dari alat tangkap utama yang digunakan untuk mengeksploitasi sumber daya tersebut yaitu alat tangkap purse seine. Produktivitas alat tangkap adalah hasil tangkapan dengan satuan bobot per upaya penangkapannya, di mana upaya penangkapan di sini dapat berupa alat tangkap yaitu berupa purse seine atau berupa trip (Sparre et al., 1999). Tetapi upaya penangkapan yang akan digunakan di sini berupa alat tangkap yaitu purse seine. Untuk mengetahui tingkat produktivitas dari purse seine harus diketahui hasil tangkapan dari alat tangkap tersebut, dengan melihat faktor-faktor yang mempengaruhi hasil tangkapannya, baik berupa faktor produksi ataupun faktor sumber daya itu sendiri. Faktor-faktor produksi yang mempengaruhi hasil tangkapan di antaranya lamanya setting, lamanya mengangkat jaring, tonage kapal, kekuatan mesin, dan jumlah anak buah kapal. Sedangkan

\footnotetext{
Peneliti pada Pusat Riset Perikanan Tangkap, Jakarta
} 
faktor-faktor sumber daya di antaranya adalah laju kelahiran dan laju kematian. Selain faktor-faktor yang disebutkan di atas ada faktor-faktor lain yang mempengaruhi hasil tangkapan yang merupakan variabel untuk mendapatkan formula produktivitas purse seine.

Tujuan penelitian ini adalah 1) memberikan data dan informasi kepada pihak pengelola serta masyarakat yang menangkap ikan pelagis kecil dengan menggunakan alat tangkap purse seine di daerah pantai utara Jawa tentang faktor-faktor yang mempengaruhi hasil tangkapar, alat tangkap purse seine di daerah tersebut; dan 2) mencari suatu persamaan regresi untuk mengetahui tingkat produktivitas dari alat tangkap purse seine yang digunakan di daerah pantai utara Jawa.

\section{BAHAN DAN METODE}

\section{Komponen Kegiatan}

Penelitian ini merupakan studi kasus pada alat tangkap purse seine yang beroperasi di Pantai Utara Jawa. Beberapa kegiatan yang telah dilakukan guna menunjang pelaksanaan penelitian ini, seperti observasi dan pengumpulan data baik data primer (data kapal, data operasional, dan data hasil tangkapan) dan maupun data sekunder.

\section{Alat dan Bahan Penelitian}

Informasi tentang faktor-faktor yang mempengaruhi hasil tangkapan purse seine diperoleh dengan cara turut serta dalam kegiatan penangkapan yang dilakukan nelayan; wawancara dengan para nelayan dan mengumpulkan data dari contoh yang diperoleh. Guna memperoleh informasi tersebut, digunakan alat bantu di antaranya 1) kertas ukur; 2) timbangan; 3) GPS untuk mengetahui posisi dan kecepatan kapal; dan 4) tali dengan pemberat untuk mengukur kedalaman perairan.

\section{Pengumpulan Data}

Pada tahap awal dilakukan penetapan 1 daerah pengambilan contoh dengan cara mengevaluasi secara cepat tempat-tempat pendaratan ikan di pantai utara Jawa yang merupakan basis utama penangkapan dengan alat purse seine. Penetapan daerah pengambilan contoh didasarkan pada jumlah alat, hasil tangkapan, dan daerah penangkapan untuk ke-2 jenis alat tangkap.

Tahap berikutnya adalah memilih sejumlah contoh secara acak berdasarkan pada jenis alat dari keseluruhan unit penangkapan yang ada agar mewakili keadaan yang sebenarnya. Pada 4 unit yang dipilih sebagai contoh dicatat data mengenai GT kapal, kekuatan mesin (HP), panjang jaring, jumlah tenaga kerja, jumlah trip, dan produksinya meliputi komposisi dan bobotnya. Data diperoleh dari hasil wawancara langsung dengan nelayan, petugas tempat penangkapan ikan dan data sekunder dari Pelabuhan Perikanan Pantai Utara Jawa. Di samping wawancara, data produksi alat tangkap diperoleh dengan mengikuti operasi penangkapan ikan di laut pada 4 kapal terpilih terutama dalam upaya memperoleh komposisi jenis hasil tangkapan.

\section{Analisis Contoh}

Untuk mengetahui informasi tentang hasil tangkapan dari purse seine, diambil contoh ikan yang tertangkap untuk ditimbang dan diukur panjangnya untuk mengetahui frekuensi panjang, bobot, dan komposisi ikan hasil tangkapan.

\section{Analisis Data}

Data yang diperoleh dari penelitian ini dapat dikelompokkan menjadi 1) data kapal; 2) data operasional; dan 3) data hasil tangkapan. Selanjutnya, dilakukan analisis data untuk memperoleh informasi tentang faktor-faktor yang mempengaruhi hasil tangkapan dan untuk memperoleh suatu formula untuk mengetahui tingkat produktivitas dari purse seine.

Untuk mengetahui hubungan antara faktor produksi dengan produksi (hasil tangkapan), data dianalisis dengan menggunakan pendekatan regresi polynomial dan regresi komponen utama (principal components regression). Analisis regresi polynomial tersebut seperti ditulis Dillon \& Goldstein (1984) sebagai berikut:

$$
Y=B_{0}+B_{1} X_{1}+B_{11} X_{1}^{2}+B_{2} X_{2}+B_{22} X_{2}^{2}+\ldots+B_{p} X_{p}+B_{P F} X_{p}^{2} \ldots \ldots(1
$$

dı mand:

$$
\begin{aligned}
Y_{1} & =\text { produksi }(\mathrm{kg}) \\
X_{1} & =\text { kecepatan kapal }(\mathrm{knot}) \\
X_{2} & =\text { panjang ris atas }(\mathrm{m}) \\
X_{3} & =\text { jumlah tenaga kerja } \\
X_{4} & =\text { tonage }(\mathrm{GT}) \\
X_{5} & =\text { kekuatan mesin }(\mathrm{PK}) \\
X_{p} & =\text { Variabel ke- } p \\
p & =1,2,3, \ldots
\end{aligned}
$$

Asumsi yang digunakan 1) produksi ikan pelagis kecil hasil tangkapan purse seine masing-masing menyebar normal; 2) populasi ikan menyebar secara mierata, yaitu peluang ikan tertangkap di setiap lokasi yang diamati adalah sama; dan 3) skill atau tingkat keahlian tenaga kerja sama.

Adapun persamaan regresi komponen utama seperti yang ditulis oieh Dillon \& Goldstein (1984) yaitu sebagai berikut:

$$
Y=A_{0}+A_{1} P C_{1}+A_{2} P C_{2}+A_{3} P C_{3}+\ldots \ldots+A_{k} P C_{k} \ldots \ldots(2
$$


di mana:

$$
\begin{aligned}
P C_{k}= & \text { kombinasi linear ke- } k \text { dari } \mathrm{X}=\left(\mathrm{X}_{1}, \mathrm{X}_{2}, \mathrm{X}_{3},\right. \\
& \left.\ldots, \mathrm{X}_{\mathrm{p}}\right)
\end{aligned}
$$

Selain faktor produksi di atas ada faktor-faktor lainnya yang diperkirakan dapat mempengaruhi produksi, yang akan dijadikan sebagai variabel dalam persamaan (1).

\section{Waktu dan Lokasi}

Riset ini dilakukan di Laut Jawa dengan mengambil 2 sentra pengambilan contoh yaitu Pekalongan dan Indramayu selama 1 tahun anggaran (2004). Gambar 1 menunjukkan posisi penangkapan purse seine dan arad di Pantai Utara Jawa.

\section{HASIL DAN BAHASAN}

\section{Aspek Biologi}

Sebagai data dukung penelitian ini, diperoleh data frekuensi panjang total ikan (TL) dari hasil observasi di pantai utara Jawa. Berdasarkan pada observasi 4 kapal purse seine pada bulan September, Oktober, dan Desember 2004 hasil tangkapan purse seine yang paling dominan (sekitar $17,69 \%$ dari bobot total hasil tangkapan) adalah ikan lemuru (Sardinella longiceps) 569 ekor. Ikan lemuru yang sering tertangkap adalah yang mempunyai panjang total berkisar antara 16 sampai dengan $16,4 \mathrm{~cm}$ (Gambar 2). Selain ikan lemuru, purse seine juga menangkap ikan layang deles (Decapterus macrosoma) dalam jumlah banyak 445 ekor (sekitar 12,05\% dari bobot total hasil tangkapan) (Gambar 3).

\section{Komposisi Hasil Tangkapan}

Proses tertangkapnya ikan oleh jaring purse seine adalah menyaring ikan yang terkurung oleh jaring (lihat cara pengoperasian purse seine pada Lampiran 3). Jenis ikan yang tertangkap oleh jaring purse seine selama dilakukan observasi di antaranya ikan lemuru (Sardinella longiceps) $17,69 \%$, layang deles (Decapterus macrosoma) 12,05\%, kembung perempuan (Restrelliger brachysoma) 8,89\%, kembung lelaki (Rastrelliger kanagurta) $8,15 \%$, layang benggol (Decapterus russelli) 7,35\%, tenggiri batang (Scomberomorus lineatus) $3,81 \%$, nyunglas (Acanthocybium solandri) 2,65\%, tongkol pisang (Auxis thazard) $3,51 \%$, dan jenis ikan lainnya (Selar crumenopthalmus, Dussumieria acuta, Sardinella fimbriata, Hilsa toli, Saurida undusquamis, Saurida sp., Chirosentrus dorab, Priacanthus tayenus, Formio niger, dan Loligo sp.) (Gambar 4).

\section{Analisis}

Hasil pengamatan menunjukkan bahwa faktorfaktor yang mempengaruhi hasil tangkapan purse seine adalah panjang ris atas, lama setting, lama tarik kolor, lama angkat jaring, tonage kapal, kekuatan mesin, jumlah lampu, total daya lampu, jumlah anak buah kapal, dan kecepatan tawur (data disajikan pada Tabel Lampiran 1 dan 2)

Faktor-faktor tersebut di atas merupakan variabelvariabel yang digunakan dan dianalisis untuk menduga hasil tangkapan dalam upaya mendapatkan formula produktivitas dari alat tangkap tersebut. Data dianalisis dengan menggunakan pendekatan regresi komponen utama, yang terdiri atas analisis komponen utama dan regresi. Analisis komponen utama

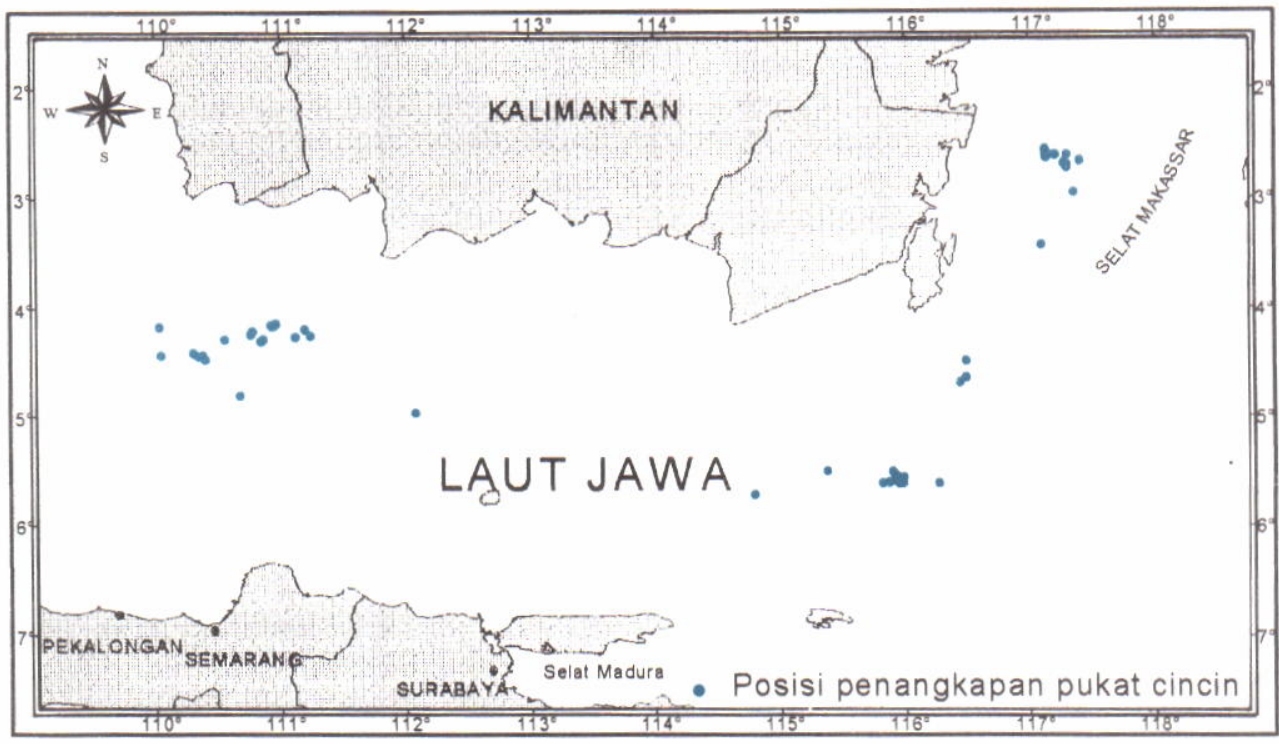

Gambar 1. Peta posisi penangkapan purse seine di pantai utara Jawa

Figure 1. Fishing ground of purse seine on the north coast of the Java Sea. 

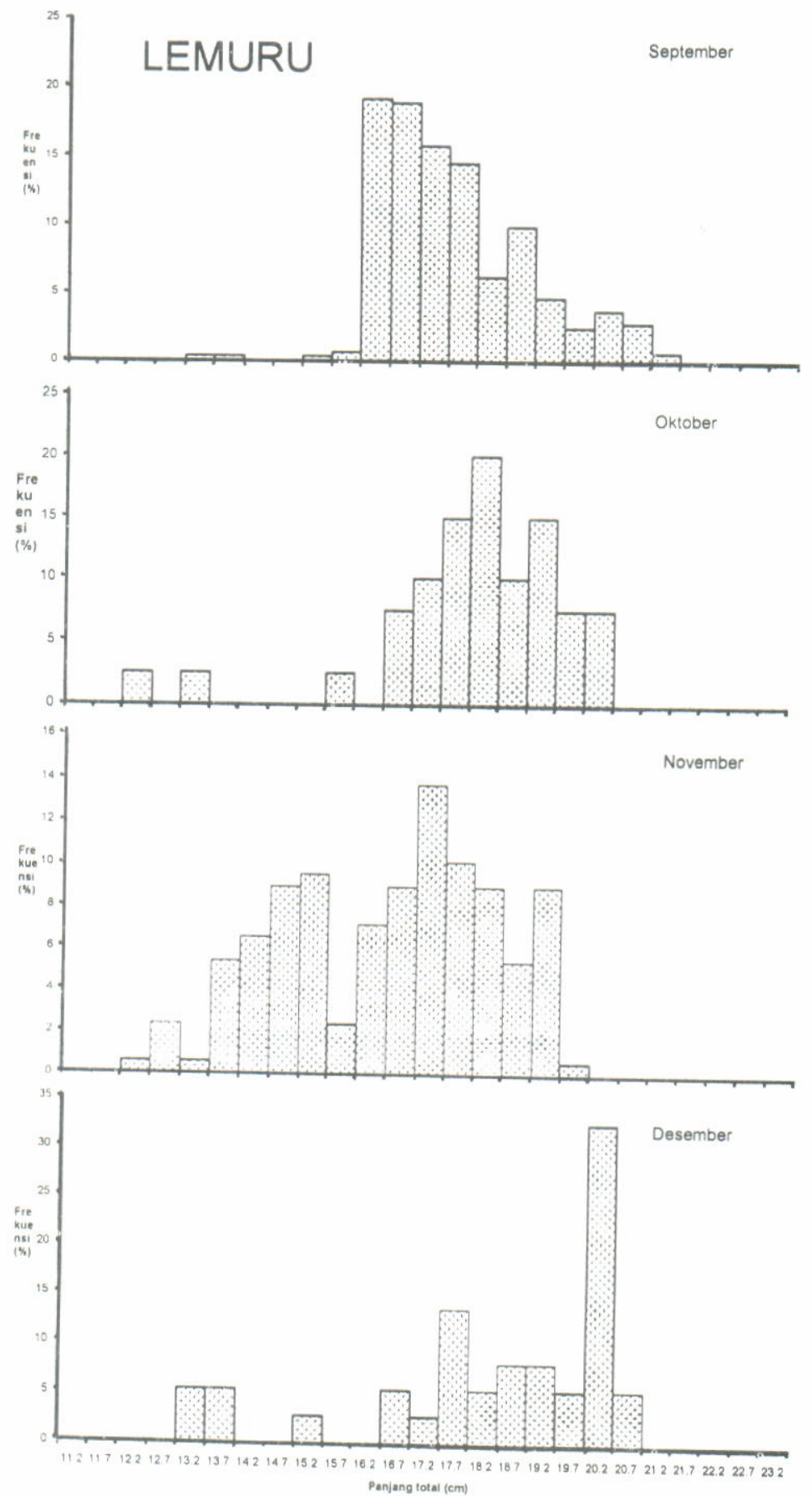

Gambar 2. Frekuensi panjang total ikan lemuru (Sardinella longiceps) hasil tangkapan purse seine yang beroperasi di pantai utara Jawa. Data ini diperoleh dari observasi pada bulan September Oktober, Nopember, dan Desember 2004.

Figure 2 Total !ength frequency of Sardinella longiceps caught by purse seine on the north coast of the Java Sea on September, October, November, and December, 2004 

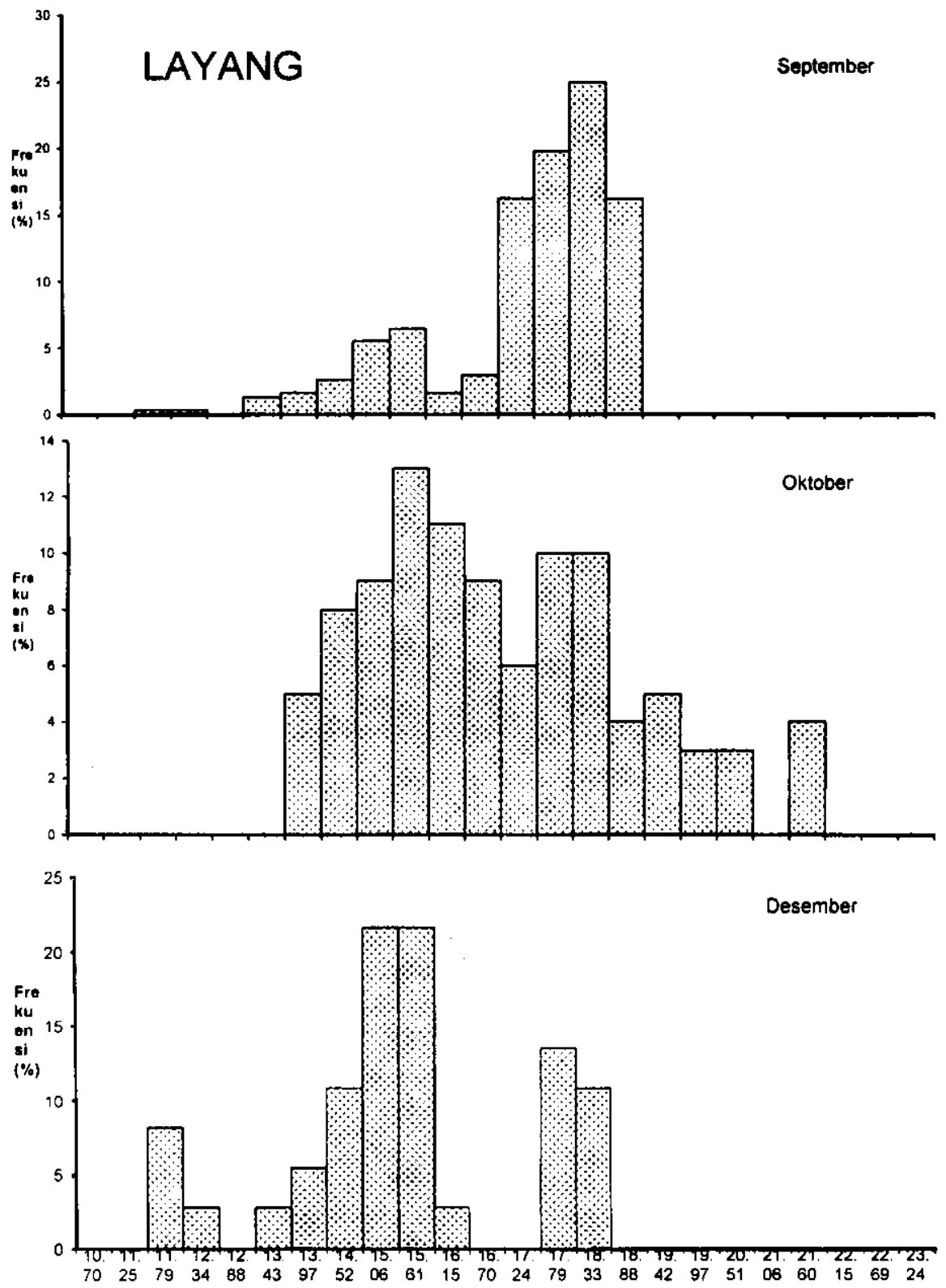

Panjang total $(\mathrm{cm})$

Gambar 3. Frekuensi panjang total ikan layang deles (Decapterus macrosoma) hasil tangkapan purse seine yang beroperasi di pantai utara Jawa. Data ini diperoleh dari observasi pada bulan September, Oktober, dan Desember 2004.

Figure 3. Total length frequency of Decapterus macrosoma caught by purse seine on the north coast of the Java Sea on September, October, and December 2004. 

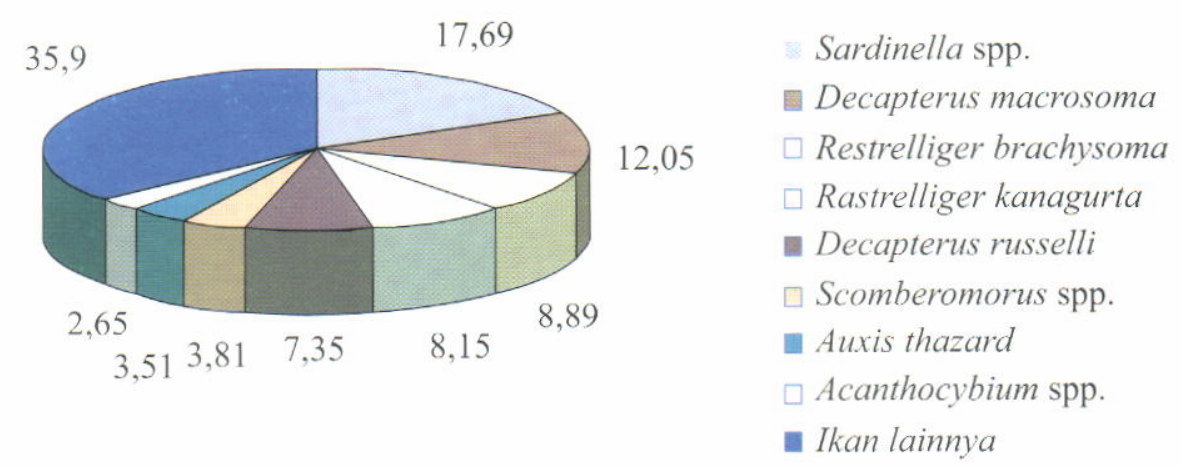

Gambar 4. Komposisi bobot hasil tangkapan purse seine (dalam \%) berdasarkan pada observasi bulan September, Oktober, Nopember, dan Desember 2004

Figure 4. Catch composition of purse seine (\%) on September, October, November, and December 2004.

bertujuan untuk mentranformasi variabel-variabel yang berkorelasi sehingga dihasilkan variabel baru yang saling bebas (tidak berkorelasi) yang merupakan kombinasi linear dari variabel-variabel asal, yang selanjutnya akan digunakan sebagai variabel untuk regresi.

Uji kenormalan data produksi ikan pelagis dengan menggunakan alat purse seine perlu dilakukan agar data dapat diuji lebih lanjut. Di bawah ini hasil dari uji kenormalan dengan memakai uji Kolmogorov (Gambar 5).
Berdasarkan pada uji kolmogorov di atas dapat disimpulkan bahwa data tidak menyebar normal dengan taraf nyata $1 \%$. Oleh karena itu, diperlukan transformasi terhadap data tersebut agar menjadi normal. Data ditransformasi dengan menggunakan transformasi logaritma sehingga diperoleh data yang normal.

$$
Z=\log (Y)
$$

Di bawah ini ditampilkan hasil uji kenormalan data hasil transformasi (Gambar 6).

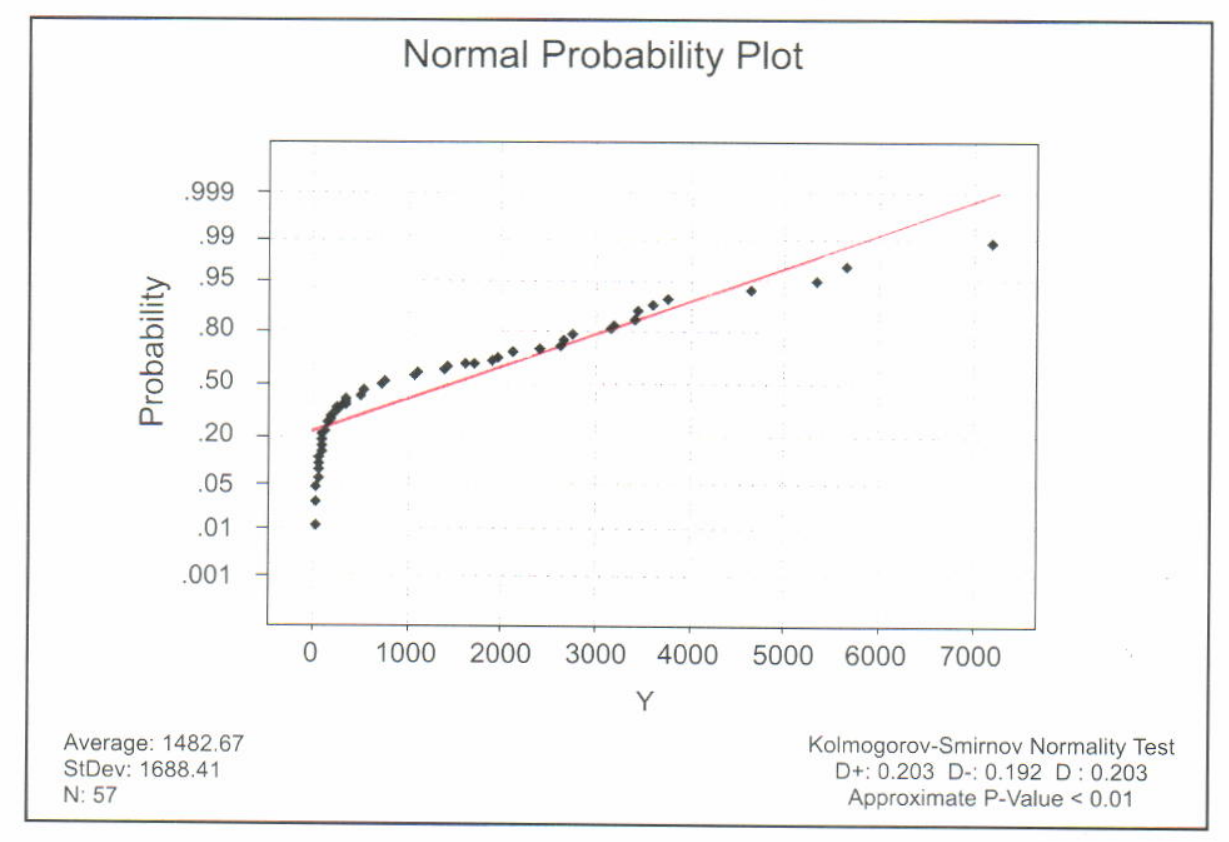

Gambar 5. Uji kenormalan data produksi ikan pelagis yang tertangkap oleh alat purse seine (Y). Figure 5. Normality test of pelagic fish production data that caught by purse seine. 


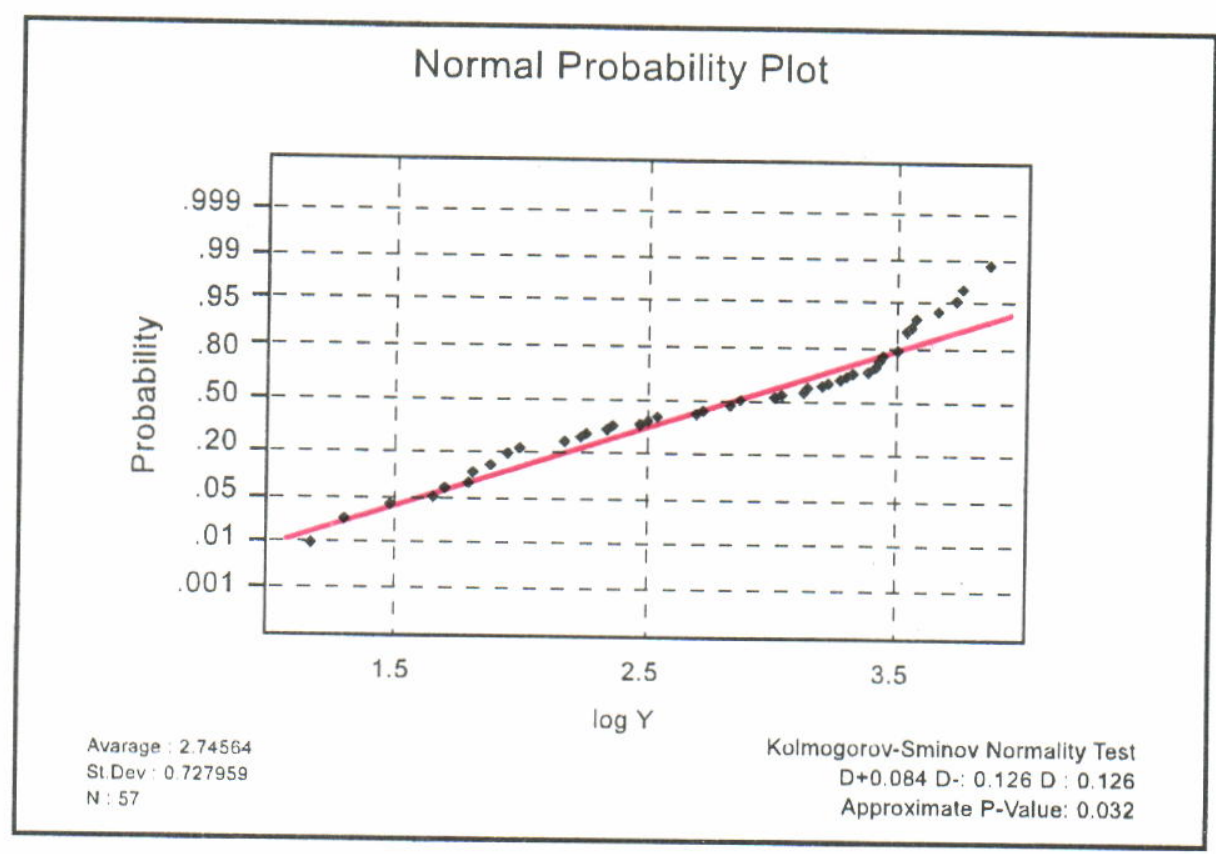

Gambar 6

Figure 6 .

Uji kenormalan data produksi ikan pelagis yang tertangkap oleh alat purse seine $(Z)$. Normality test of pelagic fish production data that caught by purse seine.

Dari Gambar 6 di atas dapat disimpulkan bahwa data hasil transformasi menyebar normal dengan taraf nyata $1 \%$. Selanjutnya, dilakukan analisis komponen utama sehingga menghasilkan persamaan dengan analisis keragaman (Tabel 1)

$$
\begin{aligned}
Z= & 3.71+0.0409 P C_{1}-0.0638 P C_{2}-0.009 P C_{3} \\
& -0.0551 P C_{4}-0.0052 P C_{5}-0.123 P C_{6}-0.128 P C_{-}
\end{aligned}
$$

di mana:

$$
\begin{aligned}
P C_{k}= & \text { kombinasi linear ke- } k \text { dari } X=\left(X_{1}, X_{2}, X_{3},\right. \\
& \left.\ldots, X_{13}\right)
\end{aligned}
$$

Selanjutnya, variabel-variabel dari persamaan (3) ditransformasi menjadi variabel asal, sehingga dihasilkan persamaan untuk menduga hasil tangkapan purse seine, yaitu:

$$
\begin{aligned}
& Z=3.71-0.000168 Y_{1}-4.03 \times 10^{5} S_{1}^{2}+0.0199657 . Y^{\circ} \\
& \text { Z. }=\log (Y) \\
& Y \quad=\text { hasil tangkapan total }(\mathrm{kg})
\end{aligned}
$$$$
-0.010884 \mathrm{X}_{3}+0.0057261 \mathrm{I}_{4}-0.012293 \mathrm{Y}_{\mathrm{s}}-0.002851 \mathrm{I}_{6}
$$$$
+0.0017926 X_{11}+0.001439 . X_{11}{ }^{2}+0.0221578 . X_{12}-0.198071 . X_{13}
$$

Tabel 1.

$$
\text { Daftar analisis keragaman }
$$

Table 1. List of variance analysis
$=$ panjang ris atas $(\mathrm{m})$

= lama setting (menit)

= lama tarik kolor (menit)

= lama angkat jaring (menit)

$=$ tonage $\mathrm{kapal}(\mathrm{GT})$

$=$ kekuatan mesin (PK)

= jumlah lampu $1.000 \mathrm{~W}$

= jumlah lampu $500 \mathrm{~W}$

= jumlah lampu $400 \mathrm{~W}$

= jumlah lampu $100 \mathrm{~W}$

= total daya lampu ( $\mathrm{KW})$

$\mathrm{I}_{12}=$ jumlah anak buah kapal

$x_{13}=$ kecepatan tawur $(\mathrm{knot})$

Dari persamaan (4) tampak bahwa panjang ris atas dan total daya lampu (contoh lampu yang digunakan disajikan pada Gambar Lampiran 5) merupakan variabel yang kuadratik, dan variabel yang paling besar pengaruhnya terhadap hasil tangkapan purse seine di pantai utara Jawa adalah kecepatan kapal saat tawur. Kecepatan kapal merupakan faktor yang sangat mempengaruhi hasil tangkapan purse

\begin{tabular}{lccccc}
\hline \multicolumn{1}{c}{ Source } & DF & SS & MS & F & P \\
\hline Regression & 7 & 19,6289 & 2,8041 & 13,68 & 0,000 \\
Residual Error & 49 & 10,0468 & 0,2050 & & \\
\hline Total & $\mathbf{5 6}$ & $\mathbf{2 9 , 6 7 5 7}$ & & & \\
\hline Keterangan/Remark: R-Sq $=66,1 \%$ & & &
\end{tabular}




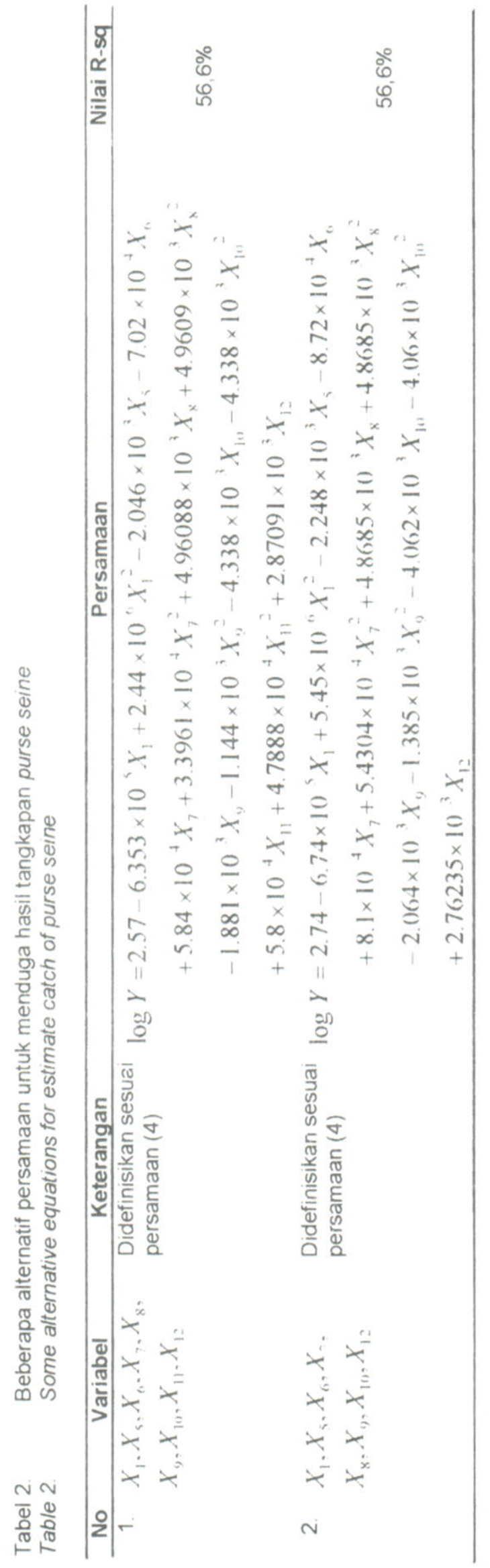


seine bukan hanya untuk di pantai utara Jawa tetapi juga berlaku di daerah Prigi, Jawa Timur (berdasarkan pada penelitian terdahulu tentang pengaruh faktor produksi terhadap produksi purse seine di Prigi, Jawa Timur (Mahiswara et al., 1987), kecepatan kapal merupakan faktor yang paling mempengaruhi keberhasilan dalam pengoperasian purse seine).

Untuk penerapan di lapangan, perhitungan hasil tangkapan dapat disederhanakan dengan memilih beberapa variabel yang mudah diukur, seperti beberapa alternatif persamaan untuk menduga hasil tangkapan purse seine yang disajikan pada Tabel 2. Alternatif persamaan pertama, variabel yang digunakan adalah panjang ris atas, tonage kapal, kekuatan mesin, jumlah lampu 1.000 W, 500 W, 400 W, dan $100 \mathrm{~W}$, total daya lampu dan jumlah anak buah kapal. Untuk alternatif persamaan ke-2, variabel yang digunakan sama dengan alternatif pertama namun tidak mengikutsertakan total daya lampu.

\section{KESIMPULAN}

Hasil tangkapan purse seine yang paling dominan (sekitar $17,69 \%$ dari bobot total hasil tangkapan) adalah ikan lemuru (Sardinella spp.) yaitu 569 ekor dengan panjang total (ikan lemuru) yang paling sering tertangkap berkisar antara 16 sampai dengan 16,4 $\mathrm{cm}$.

Persamaan untuk menduga hasil tangkapan purse seine di pantai utara Jawa sebagai berikut:

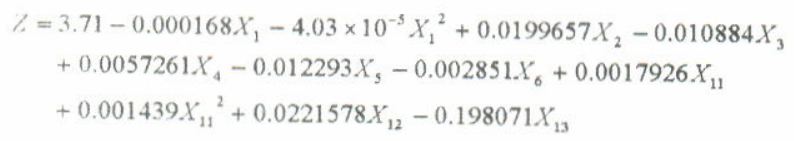

di mana panjang ris atas dan total daya lampu yang digunakan merupakan variabel-variabel kuadratik yang berarti bahwa ke-2 variabel tersebut mempunyai nilai yang dapat memaksirnumkan hasil tangkapan. Berdasarkan pada persamaan di atas variabel yang paling besar pengaruhnya terhadap hasil tangkapan purse seine di pantai utara Jawa adalah kecepatan kapal saat tawur.

\section{DAFTAR PUSTAKA}

Amin, E. M. \& Suwarso. 1990. Perubahan intensitas penangkapan ikan pelagis kecil di Laut Jawa. Jurnal Penelitian Perikanan Laut. No.56. Balai Penelitian Perikanan Laut. Jakarta.

Atmadja, S. B., Duto N., Suwarso, Tuti H., \& Mahisworo. 2003. Pengkajian stok Ikan di wilayah pengelolaan perikanan Laut Jawa. Prosiding Forum Pengkajian Stok Ikan Laut 2003. Pusat Riset Perikanan Tangkap. Jakarta.

Dillon W. R. \& M. Goldstein. 1984. Multivariate analysis: Methods and applications. John Wiley \& Sons. New York.

Sparre, Per \& Siebren C. Venema. 19.99. Introduksi pengkajian stok ikan tropis. Pusat Penelitian dan Pengembangan Perikanan. Jakarta.

Subani, Waluyo, \& H. R. Barus. 1989. Alat penangkapan ikan dan udang laut di Indonesia. Edisi khusus. Jurnal Penelitian Perikanan Laut No.50. Balai Penelitian Perikanan Laut. Jakarta.

Mahiswara, Wijopriono, \& Kusno S. 1987. Suatu analisis pengaruh faktor produksi terhadap produksi purse seine di Prigi, Jawa Timur. Jurnal Penelitian Perikanan Laut. No.39. Balai Penelitian Perikanan Laut. Jakarta. 
Lampiran 1. Data hasil observasi laut (bulan September sampai dengan Desember 2004) Appendix 1. Sea observation data (September to December 2004)

\begin{tabular}{|c|c|c|c|c|c|c|c|c|c|}
\hline \multirow{2}{*}{ Trip } & \multirow{2}{*}{ Tanggal } & \multirow{2}{*}{$\begin{array}{l}\text { Waktu } \\
\text { setting }\end{array}$} & \multicolumn{2}{|c|}{ Posisi } & \multirow{2}{*}{$\begin{array}{c}\text { Lama setting } \\
\text { (Menit) }\end{array}$} & \multirow{2}{*}{$\begin{array}{c}\text { Lama tarik } \\
\text { kolor (Menit) }\end{array}$} & \multirow{2}{*}{$\begin{array}{l}\text { Lama angkat } \\
\text { jaring (Menit) }\end{array}$} & \multirow{2}{*}{$\begin{array}{c}\text { Kecepatan } \\
\text { tawur } \\
\text { (Knot) } \\
\end{array}$} & \multirow{2}{*}{$\begin{array}{c}\text { Hasil tangkapan } \\
\text { total }(\mathrm{Kg})\end{array}$} \\
\hline & & & Bujur & Lintang & & & & & \\
\hline \multirow[t]{12}{*}{1.} & $5-9-04$ & 04 & $110^{\circ} 49,280^{\prime}$ & $-4^{\circ} 48,042^{\prime}$ & 10 & 15 & 125 & 5,5 & 350 \\
\hline & $6-9-04$ & $04 .^{15}$ & $111^{\circ} 15,904^{\prime}$ & $-4^{\circ} 15,705^{\prime}$ & 7 & 8 & 240 & 5,5 & 3.400 \\
\hline & $7-9-04$ & $04 .^{17}$ & $111^{\circ} 5,200^{\prime}$ & $-4^{\circ} 8,910^{\prime}$ & 4 & 19 & 245 & 5,5 & 7.200 \\
\hline & $8-9-04$ & $04^{10}$ & $111^{\circ} 3947^{\prime}$ & $-4^{\circ} 8,787^{\prime}$ & 7 & 13 & 120 & 5,5 & 1.400 \\
\hline & $9-9-04$ & $04^{02}$ & $111^{\circ} 5,047^{\prime}$ & $-4^{\circ} 9,599^{\prime}$ & 5 & 13 & 100 & 5,5 & 700 \\
\hline & $10-9-04$ & $04 .^{01}$ & $111^{\circ} 0,392^{\prime}$ & $-4^{\circ} 16,604^{\prime}$ & 5 & 14 & 160 & 5,5 & 3.400 \\
\hline & $11-9-04$ & $04^{07}$ & $111^{\circ} 0,088^{\prime}$ & $-4^{\circ} 16,832^{\prime}$ & 5 & 18 & 170 & 5,5 & 3.600 \\
\hline & $12-9-04$ & $04^{05}$ & $111^{\circ} 23,422^{\prime}$ & $-4^{\circ} 15,080^{\prime}$ & 5 & 15 & 140 & 5,5 & 1.100 \\
\hline & $13-9-04$ & $03^{55}$ & $111^{\circ} 5,227^{\prime}$ & $-4^{\circ} 9,644^{\prime}$ & 6 & 14 & 135 & 5,5 & 1.700 \\
\hline & $14-9-04$ & $03^{50}$ & $110^{\circ} 29,436^{\prime}$ & $-4^{\circ} 26,417^{\prime}$ & 5 & 70 & 115 & 5,5 & 300 \\
\hline & $15-9-04$ & $04^{00}$ & $110^{\circ} 32,321^{\prime}$ & $-4^{\circ} 28,201^{\prime}$ & 6 & 9 & 40 & 5,5 & 2.400 \\
\hline & $16-9-04$ & $03^{55}$ & $110^{\circ} 31,232^{\prime}$ & $-4^{\circ} 25,322^{\prime}$ & 5 & 11 & 29 & 5,5 & 1.600 \\
\hline \multirow[t]{14}{*}{2.} & $28-8-04$ & $04^{30}$ & $112^{\circ} 14,36^{\prime}$ & $-4^{\circ} 58,98^{\prime}$ & 5 & 8 & 64 & 3,0 & 65 \\
\hline & $30-8-04$ & $04^{30}$ & $116^{\circ} 27,011^{\prime}$ & $-5^{\circ} 38,003^{\prime}$ & 3 & 10 & 65 & 3,0 & 30 \\
\hline & $1-9-04$ & $04^{30}$ & $116^{\circ} 0,011^{\prime}$ & $-5^{\circ} 38,003^{\prime}$ & 3 & 10 & 63 & 3,0 & 178 \\
\hline & $2-9-04$ & $03^{.7}$ & $116^{\circ} 3,081^{\prime}$ & $-5^{\circ} 37,067^{\prime}$ & 3 & 8 & 80 & 3,0 & 150 \\
\hline & $3-9-04$ & $20 .^{15}$ & $116^{\circ} 8,025^{\prime}$ & $-5^{\circ} 35,040^{\prime}$ & 3 & 7 & 72 & 4,0 & 50 \\
\hline & 4-9-04 & $033^{40}$ & $116^{\circ} 6,097^{\prime}$ & $-5^{\circ} 34,005^{\prime}$ & 3 & 5 & 63 & 3,0 & 75 \\
\hline & $4-9-04$ & $20^{36}$ & $116^{\circ} 5,014^{\prime}$ & $-5^{\circ} 31,082^{\prime}$ & 4 & 7 & 61 & 3,0 & 230 \\
\hline & 5-9-04 & $03^{30}$ & $116^{\circ} 6,075^{\prime}$ & $-5^{\circ} 33,092^{\prime}$ & 4 & 7 & 62 & 3,0 & 15 \\
\hline & $6-9-04$ & $03^{30}$ & $116^{\circ} 9,059^{\prime}$ & $-5^{\circ} 36,036^{\prime}$ & 3 & 8 & 60 & 3,0 & 45 \\
\hline & $6-9-04$ & $19 .^{45}$ & $116^{\circ} 9,059^{\prime}$ & $-5^{\circ} 36,036^{\prime}$ & 3 & 8 & 60 & 3,0 & 20 \\
\hline & $7-9-04$ & $03^{30}$ & $116^{\circ} 10,035^{\prime}$ & $-5^{\circ} 38,096^{\prime}$ & 3 & 8 & 70 & 4,0 & 225 \\
\hline & $7-9-04$ & $20{ }^{45}$ & $116^{\circ} 10,097$ & $-5^{\circ} 34,032^{\prime}$ & 4 & 8 & 62 & 4,0 & 750 \\
\hline & $8-9.04$ & $20 .^{15}$ & $116^{\circ} 8,080^{\prime}$ & $-5^{\circ} 37,005^{\prime}$ & 4 & 7 & 94 & 3,0 & 700 \\
\hline & $9-9-04$ & $03{ }^{40}$ & $116^{\circ} 8.092^{\prime}$ & $-5^{\circ} 38,006^{\prime}$ & 4 & 9 & 61 & 3,0 & 500 \\
\hline \multirow[t]{19}{*}{3.} & $24-10-04$ & $02^{58}$ & $114^{\circ} 58,001^{\prime}$ & $-5^{\circ} 44,041^{\prime}$ & 4 & 6 & 100 & 5,0 & 525 \\
\hline & $24-10-04$ & $03^{.04}$ & $115^{\circ} 33,044^{\prime}$ & $-5^{\circ} 31,005^{\prime}$ & 4 & 6 & 77 & 5,0 & 100 \\
\hline & $25-10-04$ & $03^{18}$ & $116^{\circ} 38,036^{\prime}$ & $-4^{\circ} 42,019^{\prime}$ & 4 & 6 & 80 & 6,0 & 62 \\
\hline & $26-10-04$ & $03 .^{17}$ & $116^{\circ} 41,047^{\prime}$ & $-4^{\circ} 39,075^{\prime}$ & 4 & 7 & 88 & 6,0 & 150 \\
\hline & $27-10-04$ & $03^{32}$ & $116^{\circ} 41,048^{\prime}$ & $-4^{\circ} 30,059^{\prime}$ & 3 & 7 & 84 & 6,0 & 75 \\
\hline & $28-10-04$ & $03^{40}$ & $117^{\circ} 18,054^{\prime}$ & $-3^{\circ} 26,099^{\prime}$ & 3 & 7 & 88 & 6,0 & 177 \\
\hline & $29-10-04$ & $03 .^{10}$ & $117^{\circ} 34,072^{\prime}$ & $-2^{\circ} 57,003^{\prime}$ & 4 & 7 & 80 & 6,0 & 67 \\
\hline & $30-10-04$ & $03^{.88}$ & $117^{\circ} 37,036^{\prime}$ & $-2^{\circ} 40,022^{\prime}$ & 4 & 7 & 75 & 6,0 & 320 \\
\hline & $31-10-04$ & $03^{13}$ & $117^{\circ} 31,065^{\prime}$ & $-2^{\circ} 42,089^{\prime}$ & 4 & 7 & 82 & 5,0 & 1.050 \\
\hline & $1-11-04$ & $03{ }^{42}$ & $117^{\circ} 31,050^{\prime}$ & $-2^{\circ} 43,083^{\prime}$ & 4 & 5 & 109 & 6,0 & 1.900 \\
\hline & $2-11-04$ & U3. ${ }^{23}$ & $117^{\circ} 31,001^{\prime}$ & $-2^{\circ} 37,011^{\prime}$ & 3 & 7 & 70 & 5,0 & 100 \\
\hline & $3-11-04$ & $199^{23}$ & $117^{\circ} 21,069^{\prime}$ & $-2^{\circ} 36,010^{\prime}$ & 3 & 7 & 67 & 6,0 & 90 \\
\hline & $3-11.04$ & $199^{23}$ & $117^{\circ} 21,069^{\prime}$ & $-2^{\circ} 36,010^{\prime}$ & 3 & 7 & 102 & 5,0 & 88 \\
\hline & 4-11-04 & $3^{07}$ & $117^{\circ} 21,067^{\prime}$ & $-2^{\circ} 35,093^{\prime}$ & 4 & 7 & 118 & 5,0 & 2.100 \\
\hline & $4-11-04$ & $199^{42}$ & $117^{\circ} 21,041^{\prime}$ & $-2^{\circ} 35,095^{\prime}$ & 4 & 7 & 118 & 5,0 & 2.625 \\
\hline & $5-11-04$ & $3^{18}$ & $117^{\circ} 25,035^{\prime}$ & $-2^{\circ} 37,018^{\prime}$ & 4 & 7 & 85 & 5,0 & 525 \\
\hline & $5-11-04$ & $19^{00}$ & $117^{\circ} 21,022^{\prime}$ & $-2^{\circ} 38,019^{\prime}$ & 4 & 7 & 95 & 5,0 & 1.375 \\
\hline & $6-11-04$ & $3^{25}$ & $117^{\circ} 22,017^{\prime}$ & $-2^{\circ} 37,017$ & 3 & 7 & 85 & 5,0 & 325 \\
\hline & $6-11-04$ & $20^{03}$ & $117^{\circ} 20,052^{\prime}$ & $-2^{\circ} 33,095^{\prime}$ & 4 & 7 & 126 & 5,0 & 2.625 \\
\hline \multirow[t]{12}{*}{4.} & $9-12-04$ & $4^{15}$ & $110^{\circ} 11,120^{\prime}$ & $-4^{\circ} 25,657^{\prime}$ & 10 & 15 & 110 & 7,5 & 750 \\
\hline & $9-12-04$ & $10^{30}$ & $110^{\circ} 10,416^{\prime}$ & $-4^{\circ} 10,136^{\prime}$ & 12 & 16 & 152 & 7,5 & 3.200 \\
\hline & $10-12-04$ & $4^{15}$ & $110^{\circ} 27,281^{\prime}$ & $-4^{\circ} 24,320^{\prime}$ & 11 & 19 & 190 & 7,5 & 5.650 \\
\hline & $10-12-04$ & $11{ }^{25}$ & $110^{\circ} 42,325^{\prime}$ & $-4^{\circ} 16,636^{\prime}$ & 10 & 16 & 174 & 7,5 & 3.450 \\
\hline & $11-12-04$ & $4^{30}$ & $110^{\circ} 55,345^{\prime}$ & $-4^{\circ} 12,255^{\prime}$ & 9 & 10 & 171 & 7,5 & 2.750 \\
\hline & $11-12-04$ & $11^{00}$ & $110^{\circ} 54,521^{\prime}$ & $-4^{\circ} 14,450^{\prime}$ & 10 & 2 & 198 & 7,5 & 4.650 \\
\hline & $12-12-04$ & $4 .^{10}$ & $111^{\circ} 6,681^{\prime}$ & $-4^{\circ} 8,456^{\prime}$ & 9 & 13 & 183 & 7,5 & 5.350 \\
\hline & $12-12-04$ & $10^{45}$ & $110^{\circ} 59,486^{\prime}$ & $-4^{\circ} 17,546^{\prime}$ & 10 & 15 & 175 & 7,5 & 3.150 \\
\hline & $13-12-04$ & $4^{20}$ & $110^{\circ} 59,255^{\prime}$ & $-4^{\circ} 17,576^{\prime}$ & 9 & 11 & 170 & 7,5 & 2.750 \\
\hline & $13-12-04$ & $10^{50}$ & $111^{\circ} 20,156^{\prime}$ & $-4^{0} 11,451^{\prime}$ & 9 & 11 & 175 & 7,5 & 1.950 \\
\hline & $14-12-04$ & $4 .^{10}$ & $110^{\circ} 59,865^{\prime}$ & $-4^{\circ} 17,256^{\prime}$ & 10 & 11 & 174 & 7,5 & 3.750 \\
\hline & $15-12-04$ & $4^{10}$ & $110^{\circ} 30,630^{\prime}$ & $-4^{\circ} 26,320^{\prime}$ & 9 & 12 & 194 & 7,5 & 2.650 \\
\hline
\end{tabular}




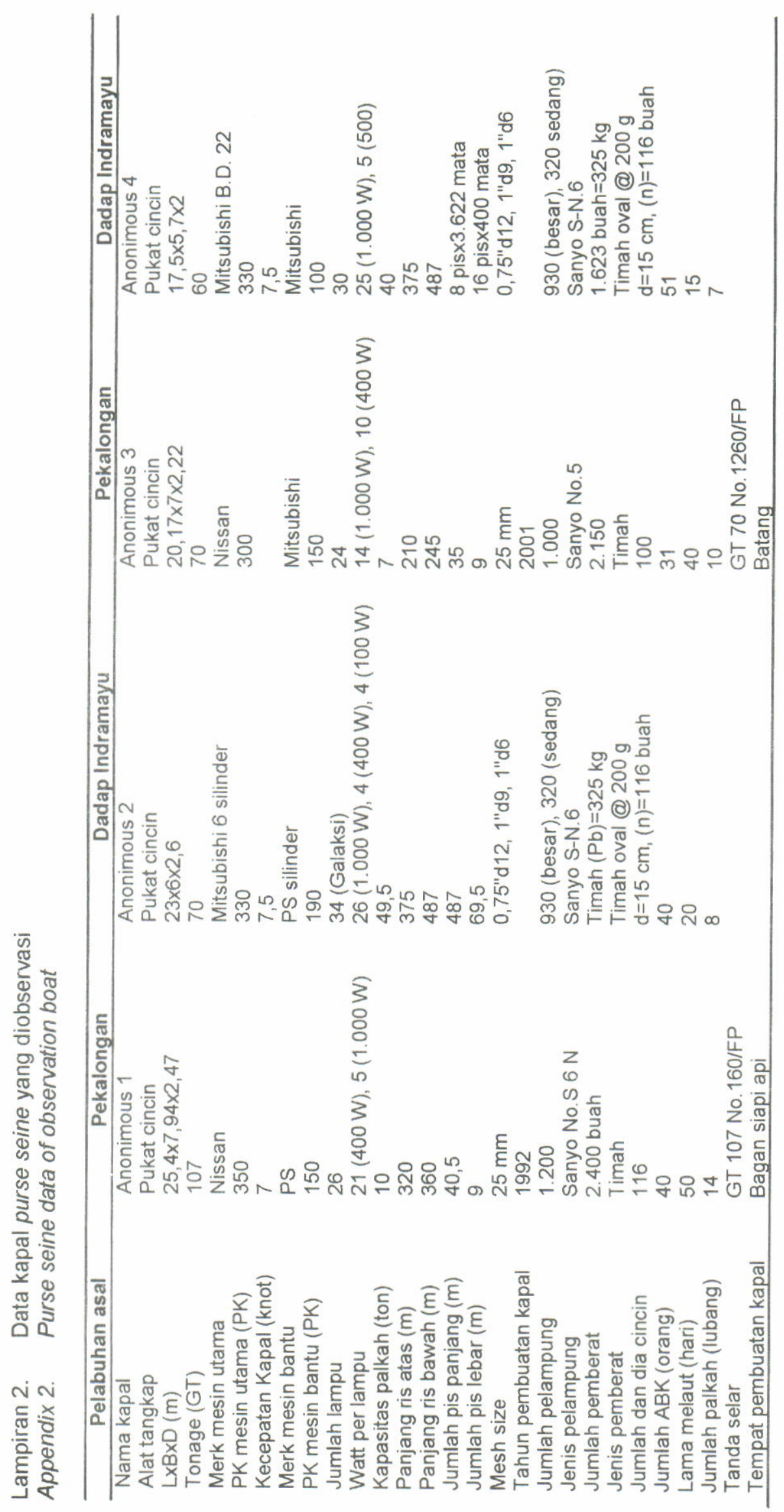



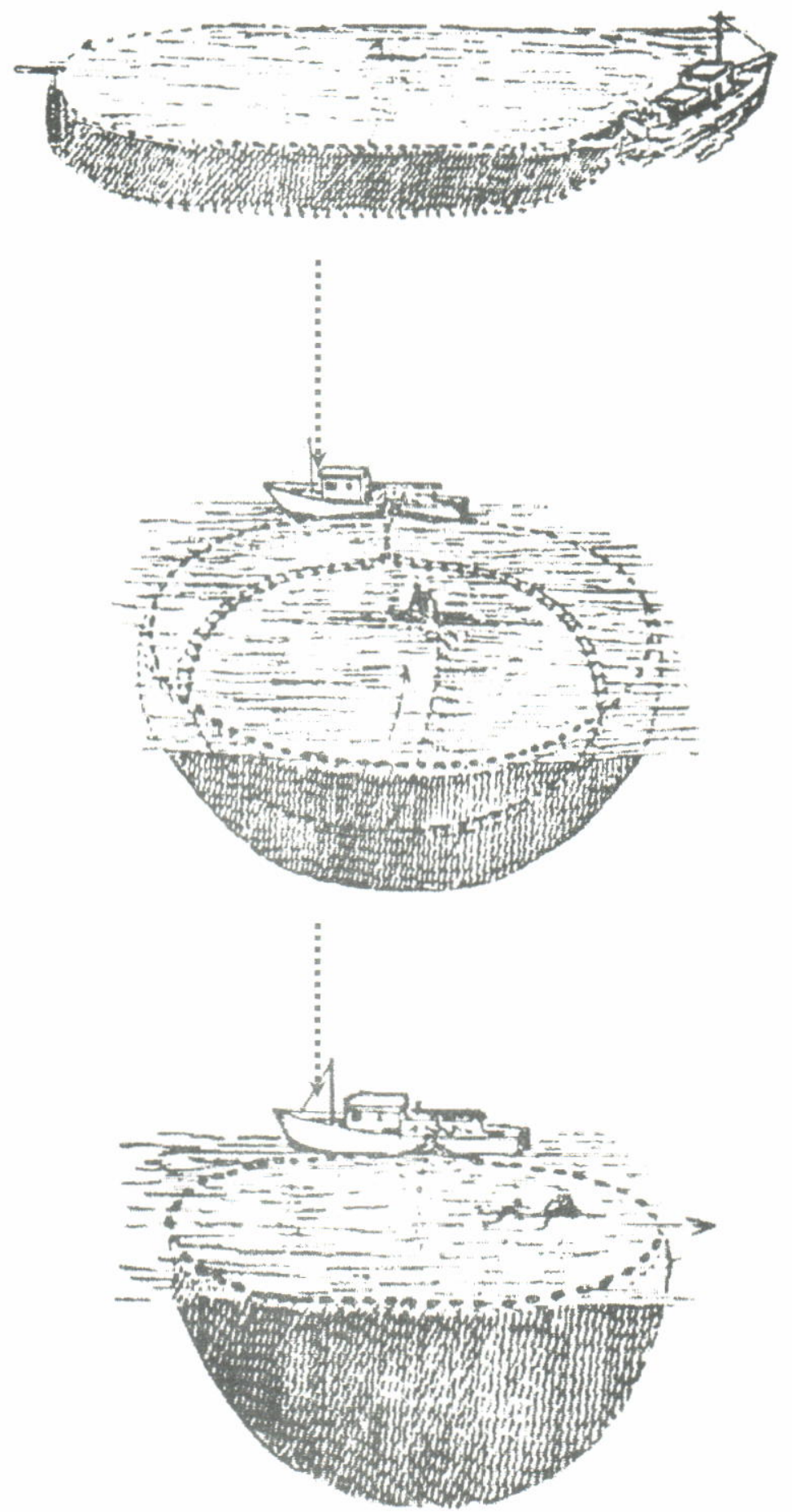

Lampiran 3. Cara pengoperasian purse seine.

Appendix 3. Operasional of purse seine

(Sumber: Subani et al., 1989) 


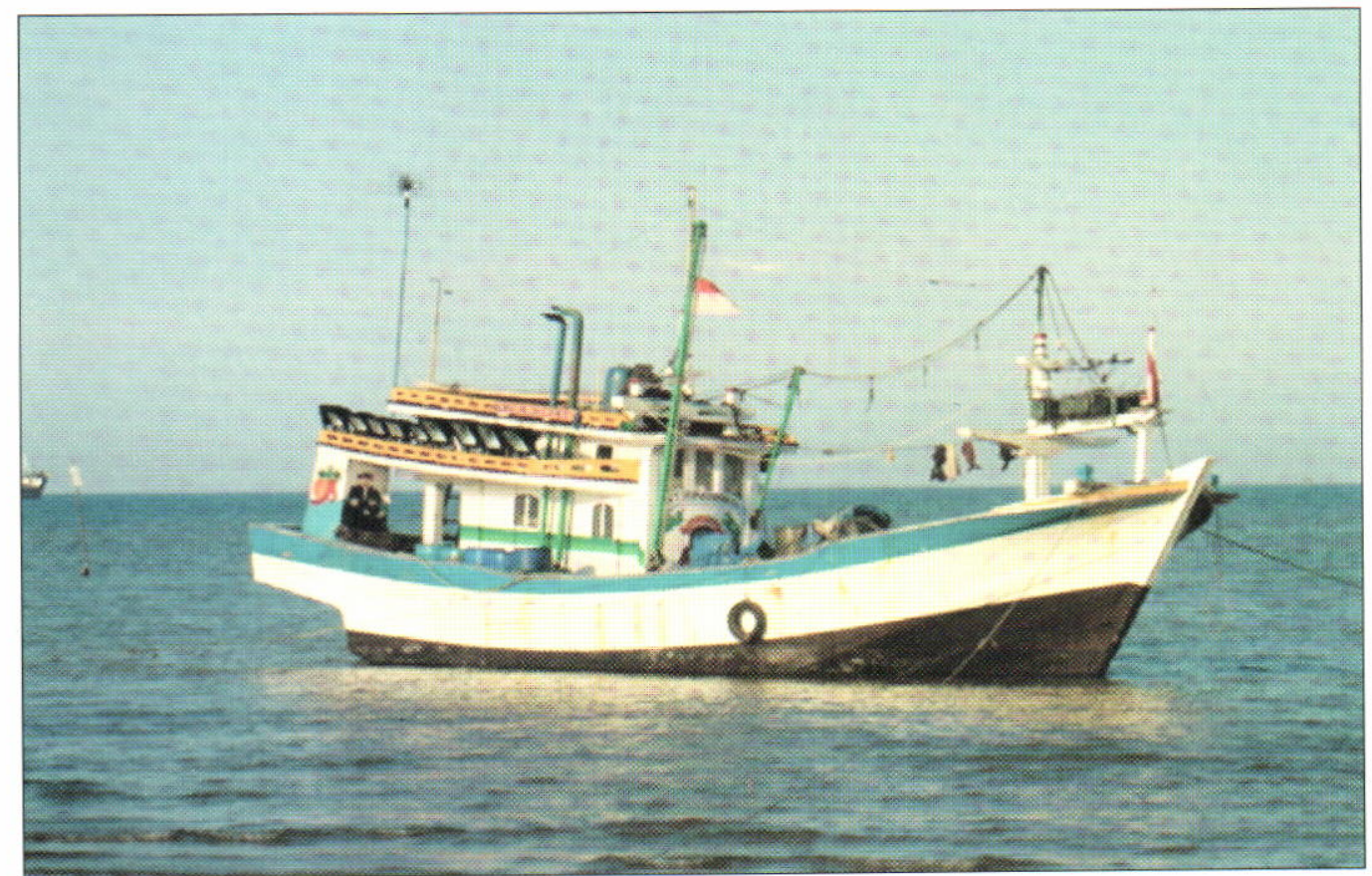

Lampiran 4. Contoh kapal purse seine yang beroperasi di pantai utara Jawa.

Appendix 4. Sample of purse seine boat that operated in the north coast of the Java.

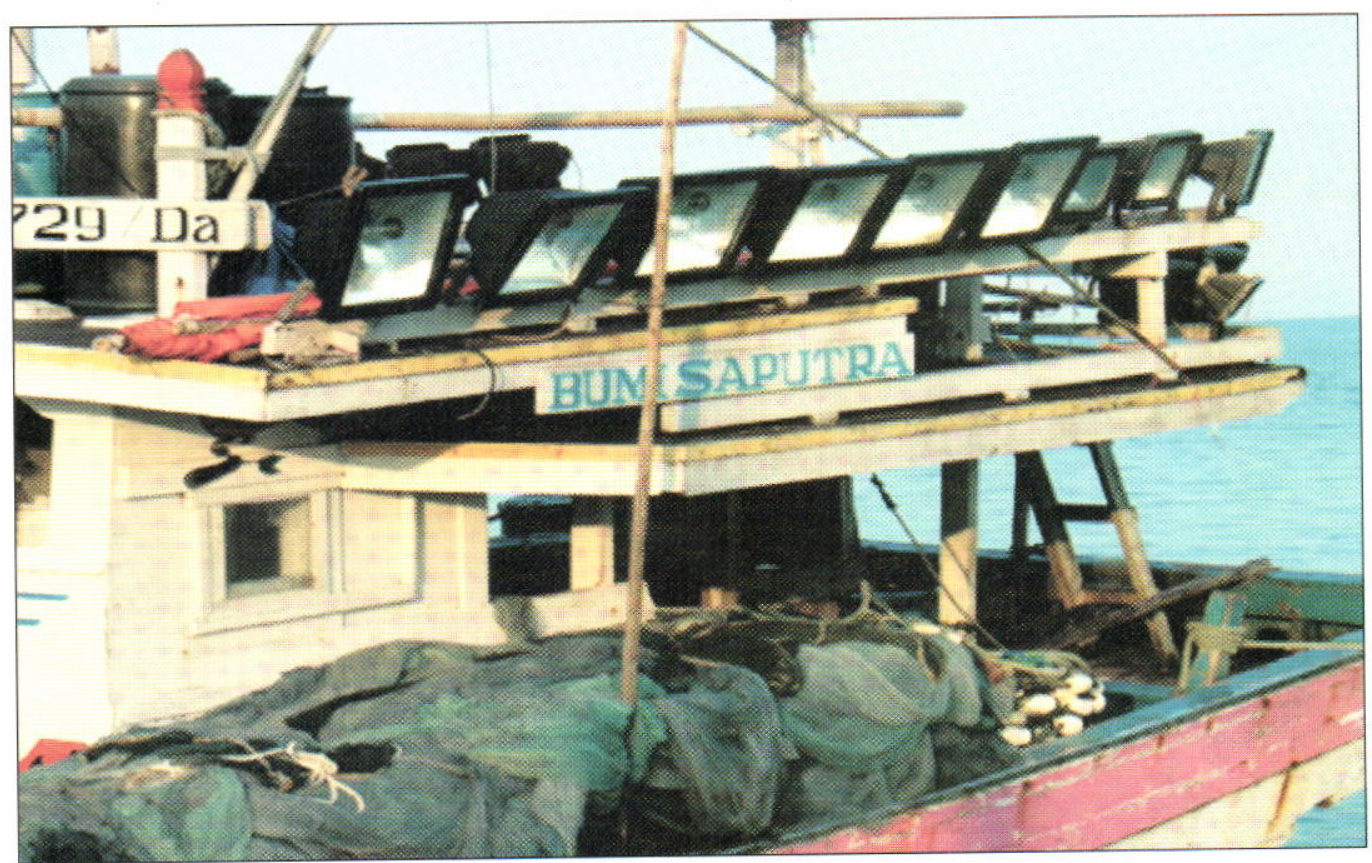

Lampiran 5. Contoh lampu halogen yang digunakan oleh kapal purse seine di pantai utara Jawa Appendix 5. Sample of halogen lamp that used by purse seine boat in the north coast of the Java. 
